\title{
On the robustness of international portfolio diversification benefits to regime-switching volatility
}

\author{
Thomas J. Flavin ${ }^{\mathrm{a}, *}$, Ekaterini Panopoulou ${ }^{\mathrm{b}}$ \\ a Department of Economics, NUI Maynooth, Maynooth, Co. Kildare, Ireland \\ ${ }^{\mathrm{b}}$ Department of Statistics and Insurance Science, University of Piraeus, Greece \\ Received 11 May 2007; accepted 24 September 2007 \\ Available online 29 September 2007
}

\begin{abstract}
We examine if the benefits of international portfolio diversification are robust to time-varying asset return volatility. Since diversified portfolios are subject to common cross-country shocks, we focus on the transmission mechanism of such shocks in the presence of regime-switching volatility. Generally, market linkages are stable with little evidence of increased market interdependence in turbulent periods. Furthermore, risk reduction is consistently delivered for the US investor who holds foreign equity.
\end{abstract}

(C) 2007 Elsevier B.V. All rights reserved.

JEL classification: $\mathrm{F} 42 ; \mathrm{G} 15 ; \mathrm{C} 32$

Keywords: Market comovement; Shift contagion; Financial market crises; International portfolio diversification; Regime switching

\section{Introduction}

We investigate the robustness of equity market linkages and their influence on international portfolio diversification benefits in the presence of regime-switching volatility. International diversification has long been advocated as an effective way to achieve higher risk-adjusted returns than domestic investment alone. The main premise underlying this strategy is that international stocks tend to display lower levels of co-movement than stocks trading on the same market. To the extent that countries are subject to different shocks, international diversification facilitates risk sharing

\footnotetext{
* Corresponding author. Tel.: +353 1 7083369; fax: +35317083934.

E-mail addresses: thomas.flavin@nuim.ie (T.J. Flavin), apano@unipi.gr (E. Panopoulou).
} 
among global investors and idiosyncratic shocks may be diversified away. Empirical evidence in support of international diversification strategies extends back to Grubel (1968). More recent empirical papers find that these benefits are still present despite increasing integration across financial markets in both stock markets (De Santis and Gerard, 1997) and bond markets (Levy and Lerman, 1988). However, a cautionary note was raised by King and Wadhwani (1990), who found that stock market correlations between the US, UK and Japan increased in the aftermath of the 1987 stock market crash. ${ }^{1}$ Butler and Joaquin (2002) show that commonly employed models of returns under-predict stock market correlations during bear markets. These findings have major implications for portfolio management given that if markets display increased comovement during turbulent periods, then the expected benefits of international diversification will not be delivered when most necessary.

Studies like King and Wadhwani (1990) found a significant increase in the correlation between markets following a period of turbulence and labelled this 'contagion'. However, Forbes and Rigobon (2002) stress the need to distinguish between contagion and interdependence. They show that when markets experience increased volatility, the correlation measure is biased upwards and may lead to an incorrect conclusion of financial market contagion. ${ }^{2}$ The heteroscedasticity inherent in asset returns may incorrectly imply contagion even though there has been no change in market interdependence. They introduce the term 'shift contagion' to describe a situation when cross-market linkages increase significantly above normal levels of interdependence during a period of market turbulence.

Our aim is to ascertain if international diversification benefits are robust to changes in volatility between calm and turbulent market regimes. Following Forbes and Rigobon (2001), we argue that portfolio managers should not focus on correlation coefficients but on the stability of stock market linkages. Since internationally diversified portfolios are subject to common cross-country shocks, we focus on the transmission mechanism of such shocks in an environment characterized by regime-switching volatility. If this is stable between regimes, i.e. no shift contagion, then international diversification should still be effective in reducing risk during episodes of market turbulence. Conversely, evidence of shift contagion would imply that this strategy might fail to deliver its promised benefits when most needed.

We take the perspective of a representative US investor who considers international investment across the G-7 countries. We adopt the methodology of Gravelle et al. (2006, henceforth GKM) to provide (as discussed below) an unambiguous test of structural changes in asset return co-movements between regimes. This method has many advantages over and above previous techniques employed to examine asset market contagion. Firstly, the country where the shock originated does not need to be identified or included in the analysis. Generally, studies of contagion tend to concentrate on smaller markets that are geographically close to the source of the shock but a portfolio manager is likely to be more concerned with larger countries that are typically included in asset allocation strategies due to their size and diversity. Hence, we focus on the G-7 countries, which account for approximately $80-85 \%$ of world market capitalization. The methodology still allows us to detect changes in the transmission of shocks that may have originated elsewhere. This is particularly beneficial in the late 1990s when the Asian and Russian crisis occurred. Furthermore, over our sample period, the G-7 markets experienced numerous episodes of high volatility, e.g. oil price shocks in the 1970s, the 1987 market crash, the ERM

\footnotetext{
${ }^{1}$ Lee and Kim (1993) and Longin and Solnik (1995) extend this finding to a wider range of countries.

${ }^{2}$ Goetzmann et al. (2002) show that episodes of increased cross-market correlation may not be due to increased co-movement alone but also to an expansion of the investment opportunity set.
} 
collapse, and the Gulf war in the early 90s, to name but a few key events and not just one specific crisis. Secondly, the regime switches are endogenously determined by the data and crisis dates do not have to be exogenously specified as in Forbes and Rigobon (2002) or the return distribution arbitrarily divided into regimes as in Butler and Joaquin (2002). The exogenous choice of crisis period is often contentious (see Kaminsky and Schmukler, 1999) and may be further compounded by having many shocks simultaneously impacting on equity markets.

Our results support the robustness of international diversification benefits across different market conditions. We find little statistical evidence of shift contagion between market pairs. Furthermore, we also show that the idiosyncratic shocks are more volatile and more persistent than common shocks and that over time and market conditions, international diversification strategies deliver risk reduction benefits.

Our paper is organized as follows. Section 2 presents the model. Section 3 describes the data and presents preliminary statistics. Section 4 reports our empirical findings and statistical tests for shift contagion. The economic significance of our results is examined in Section 5 while Section 6 analyses the robustness of our results to employing local currency returns. Section 7 contains our concluding remarks.

\section{Econometric methodology}

The model developed by GKM (2006) is ideally suited to testing for stability in the transmission of common shocks between pairs of markets across volatility regimes. Here, we outline this bivariate model. Let $r_{1 t}$ and $r_{2 t}$ represent stock market returns from countries 1 and 2, respectively. These can be decomposed into an expected component, $\mu_{i}$, and an unexpected one, $u_{i t}$, reflecting unexpected information becoming available to investors, i.e.

$$
r_{i t}=\mu_{i}+u_{i t}, \quad E\left(u_{i t}\right)=0, \quad i=1,2 \quad \text { and } \quad E\left(u_{1 t}, u_{2 t}\right) \neq 0
$$

The existence of contemporaneous correlation between the forecast errors $u_{1 t}$ and $u_{2 t}$ suggests that common structural shocks are driving both returns. Hence, we can decompose the forecast errors into two structural shocks, one idiosyncratic and one common. Let $z_{c t}$ and $z_{i t}, i=1,2$ denote the common and idiosyncratic shocks respectively and let $\delta_{c i t}$ and $\delta_{i t}, i=1,2$ denote the impacts of these shocks on asset returns. Then the forecast errors are written as:

$$
u_{i t}=\delta_{c i t} z_{c t}+\delta_{i t} z_{i t}, \quad i=1,2
$$

Both the common and the idiosyncratic shocks are allowed to switch between two volatility states. ${ }^{3}$ Furthermore, their variances are normalized to unity, which means the impact coefficients may be interpreted as the standard deviations of the shock. The structural impact coefficients $\delta_{i t}$, $\delta_{\text {cit }}, i=1,2$ are given by the following:

$$
\begin{aligned}
& \delta_{i t}=\delta_{i}\left(1-S_{i t}\right)+\delta_{i}^{*} S_{i t}, \quad i=1,2 \\
& \delta_{c i t}=\delta_{c i}\left(1-S_{c t}\right)+\delta_{c i}^{*} S_{c t}, \quad i=1,2
\end{aligned}
$$

where $S_{i t}=(0,1), i=1,2, c$ are state variables that take the value of zero in normal times and one in turbulent states. Variables with an asterisk belong to the high-volatility regime. To complete the

\footnotetext{
3 The heteroskedasticity of the structural shocks ensures the identification of our system (see also Rigobon, 2003). As argued by GKM, only the assumption of regime switching in the common shocks is necessary for the identification of the system.
} 
model, the regime paths are Markov switching and consequently are endogenously determined. Specifically, the conditional probabilities of remaining in the same state, i.e. not changing regime are defined as follows:

$$
\begin{aligned}
& \operatorname{Pr}\left[S_{i t}=0 \mid S_{i t}=0\right]=q_{i}, \quad i=1,2, c \\
& \operatorname{Pr}\left[S_{i t}=1 \mid S_{i t}=1\right]=p_{i}, \quad i=1,2, c
\end{aligned}
$$

Furthermore, we relax the assumption of constant expected returns in (1). ${ }^{4}$ This specification allows expected returns to be time varying and dependent only on the state of the common shock. In this respect, our model suggests that part of the stock market return represents a risk premium that varies with the level of volatility. In particular, expected returns are modeled as follows:

$$
\mu_{i t}=\mu_{i}\left(1-S_{c t}\right)+\mu_{i}^{*} S_{c t}, \quad i=1,2
$$

Given that idiosyncratic shocks are uncorrelated with common shocks and mainly associated with diversifiable risk, expected returns are not allowed to vary with their volatility state. Assuming that the structural shocks are normally distributed enables us to estimate the full model, given by equations (2)-(5), via maximum likelihood following the Markov-switching methodology described in Hamilton (1989).

The rationale behind detecting and testing for increased comovement due to changes in the transmission of the common shock (see also GKM) relies on the argument that, in its absence, a large common unexpected shock does not change market interdependence. In other words, the observed increase in the variance and correlation of returns during turbulent periods is due to increased impulses stemming from the common shocks and not from changes in their propagation mechanism. To empirically test for changes in the transmission of the common shock, we conduct statistical tests, specifying the null and alternative hypothesis as follows:

$$
H_{0}: \frac{\delta_{c 1}^{*}}{\delta_{c 2}^{*}}=\frac{\delta_{c 1}}{\delta_{c 2}} \text { versus } H_{1}: \frac{\delta_{c 1}^{*}}{\delta_{c 2}^{*}} \neq \frac{\delta_{c 1}}{\delta_{c 2}}
$$

The null hypothesis postulates that in the absence of shift contagion, the impact coefficients in both regimes move proportionately and their ratio remains unchanged. The likelihood ratio test is a common method for testing restrictions among nested models. It follows a $x^{2}(1)$ distribution with the restriction being the equality of the ratio of coefficients between the two regimes.

\section{Data and preliminary statistics}

Our dataset comprises weekly closing stock market index prices from the exchanges of the G-7 countries. All indices are value-weighted, obtained from Datastream International, and cover approximately $80 \%$ of total market capitalization. Our sample spans a period of more than 30 years from 1st January 1973 to 31 st December 2005, yielding a total of 1723 observations. All indices are expressed in a common currency, namely US dollars. This allows us to undertake the analysis from the perspective of a representative US investor. We prefer weekly returns to daily returns, in order to reduce the influence of non-synchronous trading across markets.

Table 1 (Panel A) presents descriptive statistics for the weekly returns, while Panel B provides some preliminary evidence on the cross-country return correlation structure. Mean returns vary

\footnotetext{
${ }^{4}$ GKM also relax this assumption when modeling the interdependence of bond returns.
} 
Table 1

Summary descriptive statistics

\begin{tabular}{|c|c|c|c|c|c|c|c|}
\hline & Canada & France & Germany & Italy & Japan & UK & US \\
\hline \multicolumn{8}{|c|}{ Panel A: full sample US dollars (1st January 1973 to 31st December 2005) } \\
\hline Mean & 0.139 & 0.173 & 0.150 & 0.150 & 0.132 & 0.146 & 0.141 \\
\hline Median & 0.236 & 0.288 & 0.246 & 0.000 & 0.186 & 0.194 & 0.294 \\
\hline Maximum & 12.862 & 12.448 & 12.225 & 15.772 & 14.824 & 22.346 & 12.302 \\
\hline Minimum & -24.492 & -19.214 & -15.032 & -18.605 & -21.361 & -24.357 & -27.090 \\
\hline Std. Dev. & 2.312 & 2.946 & 2.608 & 3.010 & 3.519 & 2.735 & 2.300 \\
\hline Skewness & -0.932 & -0.462 & -0.504 & -0.031 & -0.174 & -0.141 & -1.050 \\
\hline Kurtosis & 11.916 & 5.752 & 5.676 & 5.379 & 4.842 & 10.759 & 15.779 \\
\hline Jarque-Bera & $5952.841(0.000)$ & $604.682(0.000)$ & $586.868(0.000)$ & $406.267(0.000)$ & $252.181(0.000)$ & $4324.721(0.000)$ & $12033.400(0.000)$ \\
\hline Market & Canada & France & Germany & Italy & Japan & UK & US \\
\hline \multicolumn{8}{|c|}{ Panel B: correlations } \\
\hline Canada & 1.000 & 0.437 & 0.434 & 0.301 & 0.282 & 0.468 & 0.705 \\
\hline France & & 1.000 & 0.625 & 0.339 & 0.408 & 0.525 & 0.437 \\
\hline Germany & & & 1.000 & 0.367 & 0.422 & 0.488 & 0.432 \\
\hline Italy & & & & 1.000 & 0.205 & 0.318 & 0.282 \\
\hline Japan & & & & & 1.000 & 0.366 & 0.278 \\
\hline UK & & & & & & 1.000 & 0.456 \\
\hline US & & & & & & & 1.000 \\
\hline
\end{tabular}


across countries ranging from $0.139 \%$ in Canada to $0.173 \%$ in France. The Japanese market displays the highest volatility, while US and Canadian markets appear to be the least volatile. The Jarque-Bera test rejects normality for all markets, which is usual in the presence of both skewness and excess kurtosis. Specifically, return distributions are negatively skewed for all countries with Canada and the US being the most skewed. The Canadian, UK and US returns exhibit considerable leptokurtosis. These characteristics must be accommodated in any model of equity returns. The high level of kurtosis coupled with the rejection of normality in all markets suggests that returns are best modelled as a mixture of distributions, which is consistent with the existence of more than a single volatility regime.

Panel B provides preliminary evidence on the correlation structure between country returns. Correlation coefficients range from 0.205 for the Italy/Japan pair to 0.705 for the Canada/US pair. The average correlation is 0.408 .

\section{Results}

\subsection{Estimates}

Table 2 contains estimates of model parameters for the expected returns. Specifically, columns 2 and 3 report the mean returns during calm periods with corresponding figures for turbulent periods in columns 4 and 5. We are presented with a number of striking features. Firstly, the low volatility regime is predominantly characterised with positive mean returns and all are statistically

Table 2

Estimates of mean returns across regimes

\begin{tabular}{|c|c|c|c|c|c|c|}
\hline Country pairs & $\mu_{1}$ & $\mu_{2}$ & $\mu_{1}^{*}$ & $\mu_{2}^{*}$ & LR & $p$-Value \\
\hline Canada/US & $0.199(0.049)$ & $0.216(0.047)$ & $-0.760(0.677)$ & $-0.427(0.659)$ & $4.738 *$ & 0.094 \\
\hline France/US & $0.306(0.061)$ & $0.232(0.046)$ & $-0.596(0.195)$ & $-0.425(0.172)$ & $7.703 * *$ & 0.021 \\
\hline Germany/US & $0.282(0.058)$ & $0.230(0.047)$ & $-0.390(0.138)$ & $-0.124(0.150)$ & $7.476 * *$ & 0.024 \\
\hline Italy/US & $0.243(0.067)$ & $0.221(0.048)$ & $-0.720(0.291)$ & $-0.367(0.309)$ & $8.491 * *$ & 0.014 \\
\hline Japan/US & $0.251(0.101)$ & $0.220(0.051)$ & $-0.176(0.246)$ & $-0.006(0.096)$ & $6.216 * *$ & 0.045 \\
\hline UK/US & $0.214(0.057)$ & $0.204(0.049)$ & $-0.590(0.284)$ & $-0.309(0.327)$ & 4.513 & 0.105 \\
\hline Canada/UK & $0.213(0.051)$ & $0.203(0.058)$ & $-0.876(0.645)$ & $-0.750(0.627)$ & $5.099 *$ & 0.078 \\
\hline France/UK & $0.328(0.066)$ & $0.254(0.058)$ & $-0.835(0.364)$ & $-0.511(0.320)$ & $11.579 * * *$ & 0.003 \\
\hline Germany/UK & $0.255(0.055)$ & $0.186(0.056)$ & $-0.606(0.389)$ & $-0.195(0.269)$ & $8.295 * *$ & 0.016 \\
\hline Italy/UK & $0.168(0.075)$ & $0.239(0.062)$ & $-4.142(0.666)$ & $-4.664(0.821)$ & 2.221 & 0.329 \\
\hline Japan/UK & $0.189(0.078)$ & $0.231(0.056)$ & $-0.839(0.377)$ & $-0.676(0.422)$ & $7.764 * *$ & 0.021 \\
\hline Canada/Japan & $0.229(0.044)$ & $0.160(0.070)$ & $-1.171(1.404)$ & $-0.980(1.591)$ & $6.887 * *$ & 0.032 \\
\hline France/Japan & $0.316(0.065)$ & $0.215(0.076)$ & $-0.698(0.325)$ & $-0.568(0.314)$ & $7.312 * *$ & 0.026 \\
\hline Germany/Japan & $0.258(0.057)$ & $0.189(0.075)$ & $-0.529(0.257)$ & $-0.320(0.219)$ & $7.551 * *$ & 0.023 \\
\hline Italy/Japan & $-0.112(0.208)$ & $0.619(0.194)$ & $0.313(0.196)$ & $-0.195(0.187)$ & $9.150 * * *$ & 0.010 \\
\hline Canada/Italy & $0.212(0.049)$ & $0.196(0.060)$ & $-1.260(0.518)$ & $-0.615(0.065)$ & 3.776 & 0.151 \\
\hline France/Italy & $0.416(0.081)$ & $0.093(0.153)$ & $-2.767(0.817)$ & $1.004(0.782)$ & $5.161 *$ & 0.076 \\
\hline Germany/Italy & $0.283(0.060)$ & $0.177(0.066)$ & $-0.657(0.287)$ & $-0.006(0.013)$ & $8.644 * *$ & 0.013 \\
\hline Canada/Germany & $0.209(0.051)$ & $0.230(0.058)$ & $-0.584(1.013)$ & $-0.919(1.212)$ & $7.184 * *$ & 0.028 \\
\hline France/Germany & $0.274(0.062)$ & $0.272(0.056)$ & $-0.160(0.180)$ & $-0.248(0.174)$ & 4.536 & 0.104 \\
\hline Canada/France & 0.229 & 0.293 & -0.742 & -1.015 & $9.135 * *$ & 0.010 \\
\hline
\end{tabular}

Standard errors are in parentheses. Likelihood ratio statistic is for the null of equality of mean returns across the regimes. The test statistic has a $\chi^{2}(2)$ distribution under the null hypothesis. Asterisks (***) denote significance at $1 \%$ level, asterisks (**) denote significance at $5 \%$ level, and asterisk $(*)$ denotes significance at $10 \%$ level. 
significant at conventional levels. On the contrary, high volatility regimes are associated with negative returns in all cases, though many are not statistically different from zero. Therefore, a feature of the returns behaviour is that turbulent periods generate negative asset returns. Secondly, we test the hypothesis that means are equal across regimes. In the vast majority of cases (17 of 21 ), this hypothesis is rejected. Consequently, we allow for differences in means across regimes when modelling equity returns.

As our focus is on the robustness of portfolio diversification benefits, we examine the filtered probabilities of being in the high-volatility regime before undertaking further statistical tests. International diversification is likely to be most beneficial if the frequency of the high-volatility regime is greater for idiosyncratic shocks than for the common shock. Fig. 1 plots the filtered probabilities of the idiosyncratic shocks being in the high-volatility regime. ${ }^{5}$ With the exception of the UK and US, which show a period of relative tranquillity post 1994, idiosyncratic shocks are most often in the turbulent state for all countries. This indicates that there is substantial country-specific risk to diversify. In contrast, the frequency of the high-volatility state for the common shock is relatively low. Fig. 2 presents the evidence. ${ }^{6}$ Almost all market pairs shared high volatility following the 1987 stock market crash - a crisis originating in the US - but again we find a sustained period of high volatility in the aftermath of the Asian and Russian crises of the late 1990s - despite these countries not being in our sample. Combining evidence from Figs. 1 and 2, it would seem that there are potential benefits to undertaking international diversification strategies as the frequency of the high-volatility regime for the diversifiable shock is much greater than that of the common shock.

Table 3 presents a more detailed description of our results. Firstly, the 'Unc. Prob.' statistic reveals the proportion of time that the common shock of each market pair is in the high-volatility state. It is calculated as $(1-P) /(2-P-Q)$, where $P$ is the probability that the respective regime will prevail over two consecutive years. It varies from $55 \%$ in the case of Japan/Italy to $0.77 \%$ for Italy/UK. Without any further analysis, this information is potentially important for a fund manager. The low frequency with which the Italy/UK common shock is in the high-volatility regime, suggests that these markets infrequently suffer bad events simultaneously and hence could be used to provide a hedge against each other's risk. On the other hand, the relatively high frequency of shared market turbulence between Japan and Italy would be worrying for a portfolio manager if, these 'crises' periods led to changes in the transmission of structural shocks. The average proportion of time that a pair of markets exhibits high common volatility is $14.3 \%$ (roughly 4.75 years), which yields sufficient observations in the high volatility regime to undertake our analysis. ${ }^{7}$

'Duration' measures the time (in years) for which a common shock persists in the high-volatility regime - Duration $=1 /(1-P)$. On average, across all pairs, it persists for 0.23 years. It ranges from periods of approximately one week for Italy/UK, Italy/France and Italy/Japan to over 1.5 years in the case of US/Japan. However, the latter is unusual with the next largest (Germany/US) being little over 6 months.

The remainder of Table 3 presents our estimates of the impact coefficients of common structural shocks for calm $(\delta)$ and turbulent $\left(\delta^{*}\right)$ times (columns 2-3 and 4-5, respectively) as well as the

\footnotetext{
5 The figures presented are generated using country $i$ ( $i$ refers to all non-US states) and the US as the market pair and using UK as the partner for US. Similar graphs are available for all pairs upon request.

6 Once more, the graphs presented are for common shocks with the US.

7 A problem with many empirical tests of contagion is one of low power due to the small crisis period; see Dungey et al. (2007).
} 

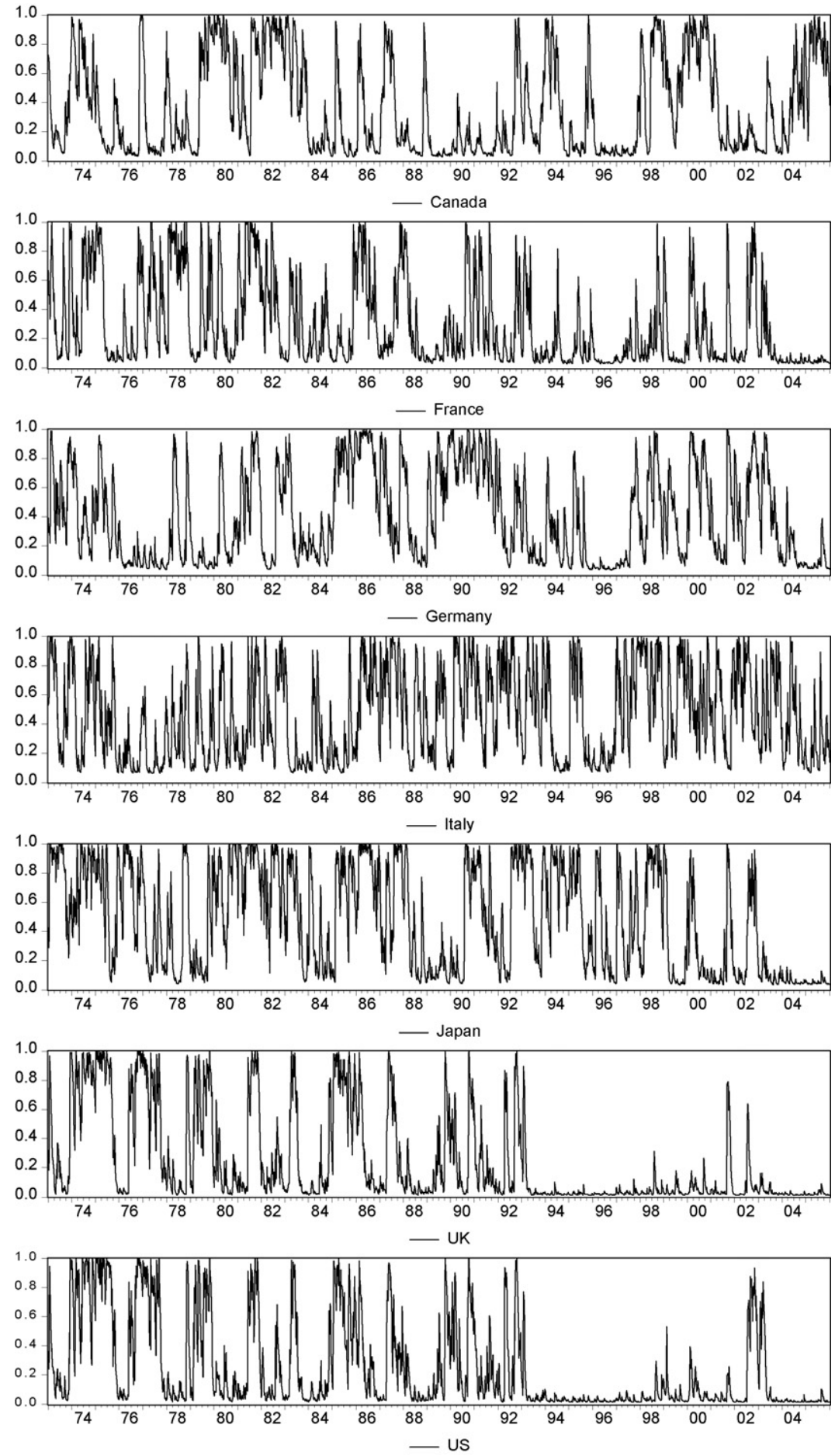

Fig. 1. Filter probabilities of high volatility idiosyncratic shocks. 

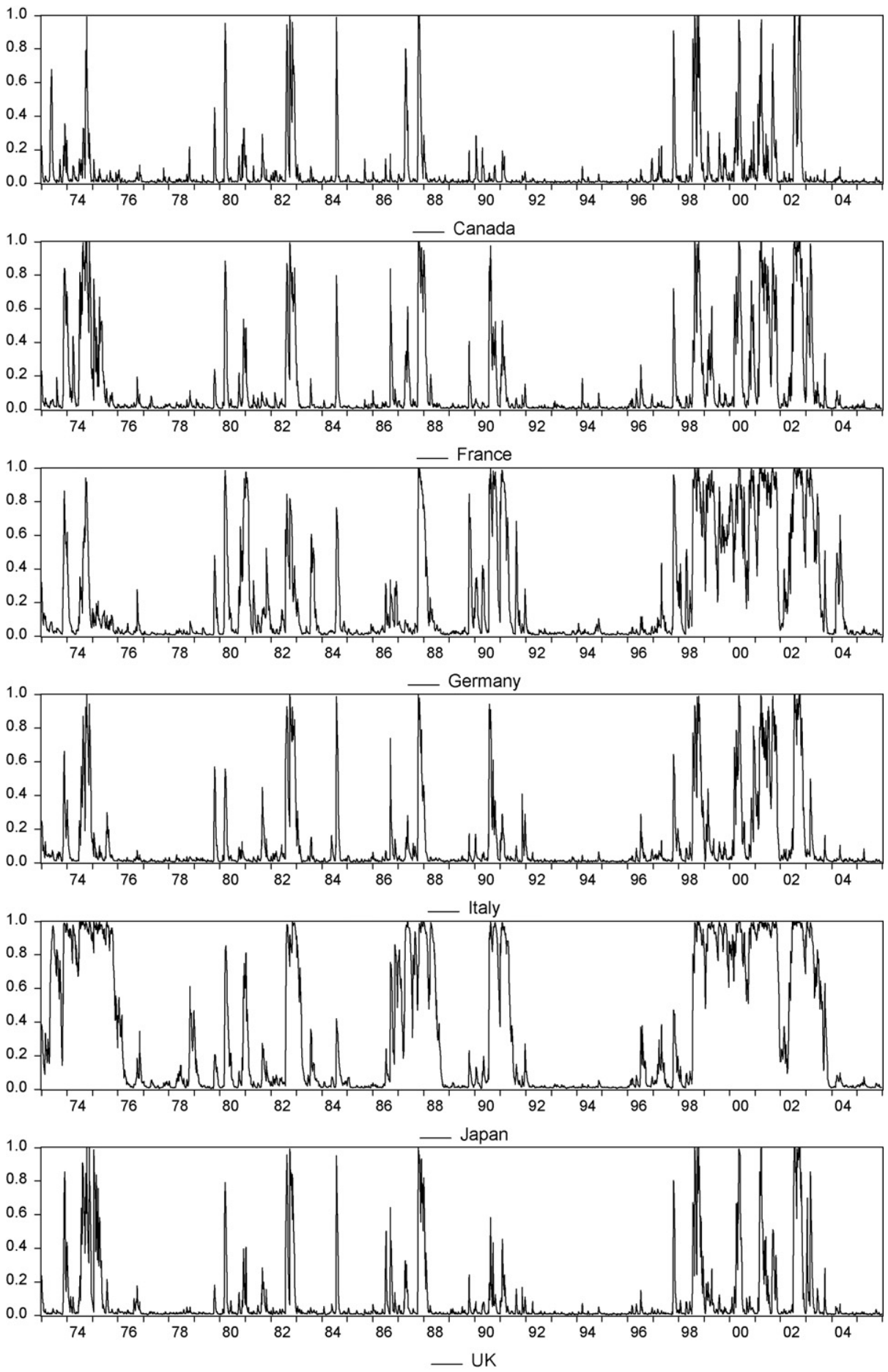

Fig. 2. Filter probabilities of high volatility common shocks. 
Table 3

Estimates of impact coefficients of common shocks

\begin{tabular}{|c|c|c|c|c|c|c|c|}
\hline Country pairs & $\delta_{c 1}$ & $\delta_{c 2}$ & $\delta_{c 1}^{*}$ & $\delta_{c 2}^{*}$ & $\gamma$ & $\begin{array}{l}\text { Unc. } \\
\text { Prob. } \\
(\%)\end{array}$ & Duration \\
\hline Canada/US & $1.453(0.099)$ & $1.523(0.104)$ & $4.284(0.441)$ & $4.482(0.479)$ & 1.001 & 7.05 & 0.12 \\
\hline France/US & $1.124(0.087)$ & $1.370(0.062)$ & $2.941(0.386)$ & $3.914(0.288)$ & 1.092 & 13.12 & 0.28 \\
\hline Germany/US & $0.930(0.028)$ & $0.976(0.087)$ & $2.719(0.199)$ & $2.868(0.151)$ & 1.004 & 21.28 & 0.54 \\
\hline Italy/US & $0.720(0.127)$ & $1.130(0.091)$ & $2.398(0.313)$ & $3.765(0.341)$ & 1.000 & 11.02 & 0.27 \\
\hline Japan/US & $1.460(0.182)$ & $0.637(0.090)$ & $1.723(0.200)$ & $2.487(0.133)$ & 3.304 & 30.45 & 1.57 \\
\hline UK/US & $1.175(0.120)$ & $1.290(0.103)$ & $3.889(0.381)$ & $4.272(0.400)$ & 1.001 & 9.10 & 0.17 \\
\hline Canada/UK & $1.367(0.100)$ & $1.211(0.121)$ & $4.384(0.491)$ & $3.883(0.582)$ & 1.001 & 7.09 & 0.11 \\
\hline France/UK & $1.599(0.126)$ & $1.471(0.099)$ & $4.183(0.347)$ & $3.846(0.285)$ & 1.001 & 16.02 & 0.15 \\
\hline Germany/UK & $1.502(0.058)$ & $1.266(0.078)$ & $3.879(0.349)$ & $3.303(0.320)$ & 1.011 & 14.90 & 0.17 \\
\hline Italy/UK & $1.261(0.236)$ & $1.544(0.283)$ & $5.308(1.863)$ & 9.387 (2.639) & 1.444 & 0.77 & 0.02 \\
\hline Japan/UK & $1.346(0.086)$ & $1.680(0.055)$ & $3.244(0.348)$ & $4.480(0.381)$ & 1.107 & 11.23 & 0.18 \\
\hline Canada/Japan & $1.407(0.049)$ & $0.936(0.044)$ & $4.539(0.387)$ & $3.885(0.262)$ & 1.287 & 6.24 & 0.09 \\
\hline France/Japan & $1.678(0.082)$ & $1.783(0.095)$ & $4.346(0.299)$ & $3.649(0.171)$ & 1.265 & 14.34 & 0.14 \\
\hline Germany/Japan & $1.601(0.055)$ & $1.629(0.065)$ & $3.755(0.254)$ & $3.650(0.219)$ & 1.047 & 16.31 & 0.31 \\
\hline Italy/Japan & $0.450(0.613)$ & $0.441(0.979)$ & $2.111(0.149)$ & $2.053(0.168)$ & 1.008 & 55.09 & 0.03 \\
\hline Canada/Italy & $1.150(0.060)$ & $0.891(0.109)$ & $5.295(0.718)$ & $3.506(0.646)$ & 1.170 & 4.06 & 0.07 \\
\hline France/Italy & $1.288(0.146)$ & $1.619(0.187)$ & $3.567(0.646)$ & $4.644(0.795)$ & 1.036 & 6.96 & 0.03 \\
\hline Germany/Italy & $1.262(0.119)$ & $1.050(0.092)$ & $3.535(0.472)$ & $2.939(0.336)$ & 1.000 & 14.64 & 0.12 \\
\hline Canada/Germany & $1.138(0.357)$ & $1.137(0.191)$ & 3.787 (1.701) & $3.840(1.033)$ & 1.016 & 8.06 & 0.16 \\
\hline France/Germany & $1.636(0.067)$ & $1.589(0.064)$ & $3.382(0.150)$ & $3.768(0.194)$ & 1.146 & 23.30 & 0.30 \\
\hline Canada/France & $1.295(0.111)$ & $1.188(0.130)$ & $3.912(0.475)$ & $3.602(0.403)$ & 1.004 & 9.43 & 0.13 \\
\hline
\end{tabular}

Standard errors are in parentheses. "Duration" refers to the duration of the high volatility common shock expressed in years. "Unc. Prob." refers to the unconditional probability of the high volatility regime expressed in percentage.

ratio, $\gamma$, (column 6) which allows us to test for shift contagion. For the low volatility regime, the estimated impact coefficients are quite tightly clustered, ranging from 0.45 to 1.78 . Furthermore all estimates are statistically different from zero. The average impact across pairs of countries is 1.27 with a standard deviation of 0.32 . Turning to the high volatility regime, we see much larger estimates and more dispersion. Both the average impact (3.80) and the standard deviation (1.20) increase three-fold. There is also considerable variation across pairs of countries. The impact of a high-volatility common shock for the US/Japan pair results in relatively small increases for both, while large responses are recorded for Italy/UK.

Column 6 of Table 3 reports the ratio of the estimated impact coefficients of common structural shocks. We construct the following statistic:

$$
\gamma=\max \left|\frac{\delta_{c 1}^{*} \delta_{c 2}}{\delta_{c 2}^{*} \delta_{c 1}}\right|,\left|\frac{\delta_{c 2}^{*} \delta_{c 1}}{\delta_{c 1}^{*} \delta_{c 2}}\right|
$$

This reveals whether or not impact coefficients in the high volatility regime are proportional to their corresponding values in the low volatility regime. A ratio of unity indicates that there is no difference in the transmission mechanism of shocks between the high- and low-volatility regimes, whereas deviations from unity would imply shift contagion in the turbulent regime. Presently, we concentrate on the economic significance of the $\gamma$ ratio but we later test for its statistical significance.

Even without a formal test, our results suggest that for many country pairs, the transmission mechanism governing common shocks does not experience major changes between high- and 
Table 4

Diagnostic tests on standardized residuals and model specification

\begin{tabular}{|c|c|c|c|c|c|c|c|}
\hline Country pairs & $\operatorname{LM}(1)$ & $\operatorname{LM}(4)$ & $\mathrm{ARCH}(1)$ & Normality & $\mathrm{RCM}_{1}$ & $\mathrm{RCM}_{2}$ & $\mathrm{RCM}_{3}$ \\
\hline Canada/US & $5.286 ; 6.472$ & $8.194 ; 9.629$ & $3.645 ; 0.178$ & $0.149 ; 0.310^{*}$ & 50.17 & 32.93 & 14.43 \\
\hline France/US & $2.052 ; 6.512$ & $8.248 ; 11.389$ & $8.781 * ; 0.010$ & $0.062 ; 0.275^{*}$ & 47.53 & 34.47 & 21.68 \\
\hline Germany/US & $0.738 ; 6.097$ & $5.896 ; 9.807$ & $5.450 ; 0.303$ & $0.138 ; 0.256^{*}$ & 56.56 & 23.70 & 28.78 \\
\hline Italy/US & $0.550 ; 6.500$ & $4.412 ; 10.058$ & $4.789 ; 0.029$ & $1.105^{*} ; 0.354^{*}$ & 61.21 & 46.85 & 19.35 \\
\hline Japan/US & $0.021 ; 6.294$ & $18.621 * ; 9.261$ & $8.571 * ; 1.612$ & $0.047 ; 0.356^{*}$ & 48.72 & 1.38 & 26.96 \\
\hline UK/US & $1.218 ; 6.763^{*}$ & $6.593 ; 10.963$ & $0.011 ; 0.055$ & $0.086 ; 0.406^{*}$ & 32.49 & 49.14 & 17.06 \\
\hline Canada/UK & $4.439 ; 1.954$ & $6.765 ; 8.586$ & $1.029 ; 0.028$ & $0.113 ; 0.092$ & 36.13 & 35.79 & 14.93 \\
\hline France/UK & $1.527 ; 0.467$ & $5.989 ; 8.023$ & $1.409 ; 0.053$ & $0.192 * ; 0.037$ & 33.78 & 16.95 & 30.29 \\
\hline Germany/UK & $0.917 ; 1.620$ & $4.737 ; 11.094$ & $0.503 ; 1.855$ & $0.200^{*} ; 0.106$ & 48.30 & 24.75 & 28.85 \\
\hline Italy/UK & $0.772 ; 1.774$ & $3.638 ; 9.785$ & $2.982 ; 0.237$ & $0.098 ; 0.157$ & 49.59 & 37.22 & 1.89 \\
\hline Japan/UK & $0.000 ; 0.204$ & $18.197 * ; 7.221$ & $7.410^{*} ; 0.061$ & $0.035 ; 0.069$ & 46.69 & 22.67 & 21.59 \\
\hline Canada/Japan & $3.881 ; 0.044$ & $6.407 ; 21.110^{*}$ & $0.764 ; 6.452$ & $0.118 ; 0.052$ & 36.46 & 48.01 & 13.93 \\
\hline France/Japan & $0.777 ; 0.010$ & $6.019 ; 18.044 *$ & $1.565 ; 5.416$ & $0.151 ; 0.068$ & 40.84 & 24.06 & 30.08 \\
\hline Germany/Japan & $1.378 ; 0.049$ & $4.974 ; 20.633 *$ & $2.189 ; 13.512 *$ & $0.155 ; 0.122$ & 44.01 & 14.16 & 27.70 \\
\hline Italy/Japan & $0.670 ; 0.088$ & $3.000 ; 11.398$ & $4.973 ; 2.368$ & $0.083 ; 0.079$ & 53.38 & 47.12 & 82.32 \\
\hline Canada/Italy & $4.207 ; 0.760$ & $7.414 ; 5.027$ & $0.797 ; 5.050$ & $0.162 ; 1.255^{*}$ & 39.65 & 57.51 & 9.77 \\
\hline France/Italy & $0.766 ; 0.631$ & $4.292 ; 5.615$ & $1.062 ; 3.234$ & $0.229 * ; 1.212 *$ & 39.57 & 58.61 & 33.68 \\
\hline Germany/Italy & $0.546 ; 0.293$ & $4.409 ; 2.953$ & $4.970 ; 0.017$ & $0.196^{*} ; 0.056$ & 32.26 & 50.25 & 16.64 \\
\hline Canada/Germany & $5.294 ; 0.548$ & $8.176 ; 3.351$ & $3.532 ; 6.772 *$ & $0.152 ; 0.166$ & 40.34 & 47.17 & 15.69 \\
\hline France/Germany & $1.331 ; 1.880$ & $8.528 ; 6.090$ & $8.351 * ; 6.605$ & $0.046 ; 0.124$ & 32.72 & 41.75 & 36.02 \\
\hline Canada/France & $4.360 ; 1.616$ & $7.440 ; 6.949$ & $1.829 ; 7.199 *$ & $0.101 ; 0.044$ & 53.16 & 36.35 & 19.57 \\
\hline
\end{tabular}

$\mathrm{LM}(k)$ is the Breusch-Godfrey Lagrange Multiplier test for no serial correlation up to lag $k, \mathrm{ARCH}(k)$ is the Lagrange Multiplier test for no ARCH effects of order $k$, Normality is the Cramer-von-Mises test for the null of Normality, RCM $i$ is the Regime Classification Measure, where $i=1,2,3$ for the idiosyncratic shock of the first, second and the common shock, respectively. Asterisk (*) denotes significance at $1 \%$ level. $\operatorname{LM}(k)$ and $\operatorname{ARCH}(k)$ have a $\chi^{2}(k)$ distribution under the null hypothesis. The Cramer-von-Mises test has a non-standard distribution and the cut-off value for RCM is 50 .

low-volatility regimes. Over half of our sample pairs (13 from 21) generate ratios of less than 1.05. If this turns out to be statistically significant evidence of shift contagion, at least it's at a relatively low level. In contrast, the US/Japan ratio is over 3.3, with seven other pairs generating increases in the ratio in excess of 5\%. Ratios of this magnitude would be of concern to a portfolio manager as they indicate adverse movements in stock returns generate unstable market linkages.

Before testing for changes in the transmission of a common shock between each pair of markets, we check if our model is appropriate for the asset returns in our analysis. Table 4 reports results from a number of diagnostic tests. Columns 2 and 3 report the LM test for serial correlation in the standardized residuals of the country pairs examined. ${ }^{8}$ For the majority of country pairs, we fail to reject the null of no serial correlation at both one and four lags. Similarly, there is little evidence of ARCH effects (see Column 4). To test for Normality, we use the Cramer-von Mises test, which is based on the overall approximation of the empirical distributions of standardized residuals to the Normal. Our results suggest that the majority of country residuals are Normally distributed. ${ }^{9}$ Hence, we argue that our regime-switching model adequately captures the distribution of asset returns. Since both common and idiosyncratic shocks move between two regimes, each country return operates in one of four regimes.

\footnotetext{
${ }^{8}$ Please note that all six sets of standardized residuals are reported for each country.

9 We also employed the Kolmogorov-Smirnov, Lilliefors, Anderson-Darling, and Watson empirical distribution tests, which yielded similar results. These results are available upon request.
} 
Table 5

Likelihood ratio tests for increased comovement

\begin{tabular}{|c|c|c|c|c|c|c|c|}
\hline Market & Canada & France & Germany & Italy & Japan & UK & US \\
\hline Canada & - & $0.000(0.991)$ & $0.000(0.983)$ & $0.008(0.927)$ & $0.001(0.977)$ & $0.000(0.995)$ & $0.001(0.973)$ \\
\hline France & & - & $6.219 * *(0.013)$ & $0.001(0.972)$ & $0.193(0.660)$ & $0.000(0.983)$ & $0.354(0.552)$ \\
\hline Germany & & & - & $0.000(1.000)$ & $0.008(0.927)$ & $0.001(0.972)$ & $0.000(0.987)$ \\
\hline Italy & & & & - & $0.000(0.995)$ & $0.928(0.335)$ & $0.000(0.996)$ \\
\hline Japan & & & & & - & $0.862(0.353)$ & $1.321(0.250)$ \\
\hline UK & & & & & & - & $4.000 * *(0.046)$ \\
\hline US & & & & & & & - \\
\hline
\end{tabular}

Likelihood ratio statistic is for the null of no increased comovement against the alternative of increased comovement for the indicated country pairs. The test statistic has a $\chi^{2}(1)$ distribution under the null hypothesis. Asterisks (***) denote significance at $1 \%$ level, asterisks $(* *)$ denote significance at $5 \%$ level, and asterisk $(*)$ denotes significance at $10 \%$ level. $p$-Values are reported in parentheses below coefficients.

To measure the regime qualification performance of our model, we employ the Regime Classification Measure (RCM) developed by Ang and Bekaert (2002). According to this measure, a good regime-switching model should be able to classify regimes sharply. For a model with two regimes, the regime classification measure $(R C M)$ is given by:

$$
\mathrm{RCM}=400 \times \frac{1}{T} \sum_{t=1}^{T} p_{t}\left(1-p_{t}\right)
$$

where the constant normalizes the statistic to lie between 0 and 100. A perfect model will have a RCM close to zero, while a model that cannot distinguish between regimes will produce a RCM close to 100 . The final three columns of Table 4 report the RCM for the idiosyncratic shocks of both countries and the common shock, respectively. Using a cut-off of 50 suggests that in most cases, our regime-switching model does well in describing the return generating process, but does perform better in capturing the behaviour of the common shock than the idiosyncratic shocks in most pairs.

\subsection{Tests for shift contagion}

In testing for changes in the transmission of a common shock between high- and low-volatility regimes, we focus on the ratio $\gamma$, and test if it is statistically different from unity. We perform a likelihood ratio test, whose test statistic has a $\chi^{2}(1)$ distribution under the null hypothesis. Table 5 presents the results.

We find little evidence of shift contagion. In the majority of cases (19 out of 21), we fail to reject the null hypothesis of no change in the ratio of market responses to a common shock. In other words, the mechanism by which common shocks are transmitted is unaffected by the switch from a low- to high-volatility regime. This is reassuring for those who undertake international equity diversification to reduce portfolio risk. Market linkages are stable for most market pairs implying benefits should be robust to changes in volatility regimes. For the other pairs - US/UK and France/Germany - we find evidence of shift contagion, which may erode the expected gains from international diversification. The ratio for the UK/US, though statistically different from unity, is quite low at 1.001. So even if these markets show evidence of changes in the transmission mechanism of the common shock, it may not deter potential investors from holding the equities of the two countries in their portfolio. On the other hand, the ratio for France/Germany is 1.146, 
Table 6

Estimates of impact coefficients of idiosyncratic shocks

\begin{tabular}{llllrrr}
\hline Country pairs & \multicolumn{1}{l}{$\delta_{1}$} & \multicolumn{1}{l}{$\delta_{2}$} & \multicolumn{1}{l}{$\delta_{1}^{*}$} & \multicolumn{1}{l}{$\delta_{2}^{*}$} & \multicolumn{1}{l}{$\begin{array}{l}\text { Unc. Prob./ } \\
\text { Duration }(1)\end{array}$} & \multicolumn{1}{l}{ Unc. Prob./ } \\
Duration $(2)$
\end{tabular}

Standard errors are in parentheses. "Duration" refers to the duration of the high volatility regime of the idiosyncratic shock expressed in years. "Unc. Prob." refers to the unconditional probability of the high volatility regime expressed in percentage.

representing quite a large shift in the diffusion process of the common shock. Consequently, US investors may need to be wary of simultaneously holding French and German equities in their portfolios.

\section{Economic significance of portfolio diversification}

Having found little statistical evidence of shift contagion, we now turn to the economic significance of our results. Firstly, we compare the relative importance of the common shock and the idiosyncratic shocks. As seen in Fig. 1, the idiosyncratic shocks for pairs involving the US tend to be in the high-volatility regime with far greater frequency than the common shock for each corresponding pair. Table 6 verifies this finding for all possible market pairs. We present the proportion of time the idiosyncratic shock spends in the turbulent regime and the persistence of the shock. On average, the idiosyncratic shock is in the high-volatility state $41.5 \%$ of the time (roughly 13.5 years). This is almost three times greater than that for the common shock. Likewise, the persistence of the country-specific shock is much greater, with an average of 1.5 years; approximately six times that of the common shock. Columns 2-5 report the impact coefficients for the idiosyncratic shocks. There is huge variation with some spectacular increases from calm to turbulent periods, e.g. for the Japan/UK pair, the impact of the idiosyncratic shock is over 45 times greater for the UK in the high- compared to the low-volatility regime. Thus, the evidence indicates that idiosyncratic shocks occur more frequently and display greater persistence than common shocks. 
Table 7

Risk reduction benefits accruing to international diversification

\begin{tabular}{|c|c|c|c|c|c|c|}
\hline$x \%$ & Canada (\%) & France $(\%)$ & Germany (\%) & Italy $(\%)$ & Japan (\%) & $\mathrm{UK}(\%)$ \\
\hline \multicolumn{7}{|c|}{ Panel A } \\
\hline 5 & 3.0 & 4.2 & 5.3 & 6.3 & 5.3 & 4.4 \\
\hline 10 & 5.5 & 7.4 & 9.8 & 11.5 & 9.1 & 8.0 \\
\hline 15 & 7.8 & 9.7 & 13.6 & 15.2 & 11.2 & 10.8 \\
\hline 20 & 9.6 & 11.1 & 16.5 & 17.8 & 11.7 & 12.8 \\
\hline 25 & 11.1 & 11.5 & 18.7 & 19.2 & 10.5 & 14.0 \\
\hline \multicolumn{7}{|c|}{ Panel B } \\
\hline 5 & 0 & 0 & 0 & 0 & 0 & 0 \\
\hline 10 & 0 & 0 & 0 & 0 & 0 & 0 \\
\hline 15 & 0 & 2 & 0 & 0 & 0 & 0 \\
\hline 20 & 0 & 6 & 0 & 0 & 5 & 3 \\
\hline 25 & 0 & 15 & 0 & 1 & 21 & 7 \\
\hline
\end{tabular}

Panel A presents the average risk reduction achieved by a US investor who holds $x \%$ of funds in the foreign asset and the remainder in domestic equity. Panel B reports the proportion of time that the diversified portfolio is more risky than the US portfolio.

To assess the risk reduction benefits of international diversification, we compare the risk of a domestic US portfolio with a portfolio comprising of US and foreign equity. From our model we compute the time-varying covariance matrix. Recall from (2), that the aggregate shock of each country return is decomposed into an idiosyncratic and common shock. Both are allowed to switch between high and low-volatility states and are assumed to be independent. Hence, our model encompasses eight states, ranging from the state when all shocks are in the low volatility regime to one when all shocks display high volatility. Each generates a different variance-covariance matrix, which is uniquely calculated from the model given by Eqs. (2)-(5). The time-varying conditional covariance matrix of returns is then computed by weighting these state matrices by the estimated filter probabilities for each type of shock. There is considerable time variation in the correlation with a noticeable increase around financial market crises. ${ }^{10}$

We then compare the risk of a domestic portfolio with a portfolio containing a foreign equity and the remainder in US equity. Table 7 presents the risk reduction benefits of international portfolio diversification for various levels of foreign equity holdings. Panel A reports the variance of the internationally diversified portfolio as a proportion of the variance of the US only portfolio. Focussing on the case where $10 \%$ of wealth is invested in non-US equity, international diversification delivers considerable reduction in risk for the US investor. The ratio is always less that unity and delivers average risk reduction ranging from 5.5\% for Canadian investment up to $11.5 \%$ for diversification into Italian equity. Risk reduction is relatively stable over time and shows little sign of collapsing during market turbulence. In fact, diversification benefits were large in the aftermath of the 1987 crash when the US investor most needed protection. This may not be surprising given that this shock originated in the US, but we also see that diversification benefits were delivered during the Asian crisis, even for the US/Japan portfolio. ${ }^{11}$ Therefore, high-volatility regimes do not appear to erode diversification benefits. In general, the average risk reduction increases with

\footnotetext{
${ }^{10}$ For brevity we omit graphs of the time-varying correlations but these are available from the authors upon request and in the working paper version of this study (available at http://economics.nuim.ie/research/workingpapers/2007.shtml).

11 A time series graph of this ratio is available in the working paper version of the paper.
} 
the level of diversification. For example, an investor who allocates her wealth between US and Italian equity reaps benefits ranging from a $6.3 \%$ decline in risk for holding $5 \%$ of the portfolio in the foreign equity to almost $20 \%$ for allocating $25 \%$ of wealth to the Italian asset. Though smaller in magnitude, this pattern is repeated for all countries. Even the UK, for which we found a statistically significant increase in its comovement with the US market, delivers risk reduction benefits for all plausible levels of diversification. ${ }^{12}$ Furthermore, Panel B of Table 7 shows us that risk reduction is observed in the majority of individual time periods. When allocating up to $10 \%$ to foreign assets, the US investor always enjoys lower portfolio risk. Increasing the allocation to non-domestic equity may reduce average risk but it also produces some periods when the diversified portfolio is more risky. However, the number of such time periods is small and even for funds with $20 \%$ held in foreign assets, the maximum proportion of time that fails to deliver risk reduction is $6 \%$ (for French equity), while investments in Canada, Germany and Italy still deliver lower risk in every period. Consequently, we conclude that international diversification consistently delivers reduced portfolio risk for US investors.

Therefore, we argue that the benefits of hedging idiosyncratic risks outweigh the burden of bearing common shocks. There is little evidence of shift contagion, which implies that turbulent periods are characterized by levels of market interdependence similar to those experienced in calm periods. Idiosyncratic shocks are found to be more frequent, more persistent and larger in magnitude than the common shock. Both our statistical and economic results reinforce the belief that international portfolio diversification strategies are worthwhile and provide the investor with insurance against domestic risk in all market conditions.

\section{Robustness}

We check the robustness of our statistical results by repeating the analysis for equity returns expressed in their local currency. While we find more statistical significance of increased comovement, the majority of pairs (13 of 21) still fail to reject the null hypothesis of no change in the transmission mechanism of the common shock. Again results are generally supportive of the notion that the process governing the diffusion of the common shock is relatively stable between regimes. 13

\section{Conclusion}

We investigate if stock market linkages between pairs of G7 equity markets are stable across volatility regimes and hence if portfolio managers should be concerned by the impact of shift contagion on international diversification strategies. We concentrate on testing for changes in the transmission mechanism of the common shock. The stability of market linkages between calm and turbulent conditions will dictate the effectiveness of diversification strategies.

We report a number of interesting findings. Firstly, expected stock returns are statistically different between regimes. Calm markets are associated with significantly positive returns while turbulent markets are characterised by negative mean returns. Secondly, our model captures the features of return distributions quite well and we find that common market shocks are, on average,

\footnotetext{
12 Given the bivariate structure of our model, we limit ourselves to two-country diversification. Therefore, these numbers may be viewed as lower bounds to the potential benefits available for a multi-country diversification strategy.

${ }^{13}$ For brevity, we do not report results here, but they are available from authors upon request.
} 
in a high-volatility regime about $23 \%$ of the time. Thirdly, we find little evidence of changes in the process governing the diffusion of common shocks between the pairs of markets under review. In $90 \%$ (19 of 21) of cases, we fail to reject the hypothesis of no shift contagion. Finally, we find that relative to the common shock, idiosyncratic shocks are more frequently in the high-volatility regime and exhibit more persistence in this state. Hence diversifiable risks represent a greater risk than common risks and thus favour international diversification. To confirm, we examine the risk reduction achieved by a US investor who allocates wealth between a foreign and domestic equity. We find that risk is substantially lower in the vast majority of cases. More importantly, risk reduction appears to be robust to market conditions.

In summary, we find strong support for the stability of market linkages and the robustness of international diversification strategies across volatility regimes. There is little evidence of shift contagion. Furthermore, the risk reduction benefits appear to be robust to changes in volatility and indeed were manifest in the aftermath of the 1987 crash when US investors were most vulnerable. Consequently, fund managers should pursue international diversification strategies without fear of potential benefits being eroded during periods of high volatility, such as those associated with bear markets.

\section{Acknowledgement}

We would like to thank an anonymous referee, Prof. Jerry Dwyer and other seminar participants at the Federal Reserve Bank of Atlanta, INFINITI conference 2006, University of Muenster and Dept. of Economics, NUI Maynooth for helpful comments on an earlier draft of this paper. We also thank James Morley for making the Gauss code available to us.

\section{References}

Ang, A., Bekaert, G., 2002. International asset allocation with regime shifts. Review of Financial studies 15, $1137-1187$.

Butler, K.C., Joaquin, D.C., 2002. Are the gains from international portfolio diversification exaggerated? The influence of downside risk in bear markets. Journal of International Money and Finance 21, 981-1011.

De Santis, G., Gerard, B., 1997. International asset pricing and portfolio diversification with time-varying risk. Journal of Finance 52, 1881-1912.

Dungey, M., Fry, R., Gonzalez-Hermosillo, B., Martin, V.L., 2007. Sampling properties of contagion tests. University of Cambridge, Cambridge, Unpublished manuscript.

Forbes, K.J., Rigobon, R.J., 2001. Measuring contagion: conceptual and empirical issues. In: Claessens, S., Forbes, K.J. (Eds.), International Financial Contagion. Kluwer Academic Publishers, Boston.

Forbes, K.J., Rigobon, R.J., 2002. No contagion, only interdependence: measuring stock market comovements. Journal of Finance 57, 2223-2261.

Goetzmann, W., Li, L., Rouwenhorst, K.G., 2002. Long-term global market correlations. NBER working paper no. 8612, National Bureau of Economic Research.

Gravelle, T., Kichian, M., Morley, J., 2006. Detecting shift-contagion in currency and bond markets. Journal of International Economics 68, 409-423.

Grubel, H., 1968. Internationally diversified portfolios: welfare gains and capital flows. American Economic Review 58, 1299-1314.

Hamilton, J.D., 1989. A new approach to the economic analysis of nonstationary time series and the business cycle. Econometrica 57, 357-384.

Kaminsky, G.L., Schmukler, S.L., 1999. What triggers market jitters? A chronicle of the Asian crisis. Journal of International Money and Finance 18, 537-560.

King, M.A., Wadhwani, S., 1990. Transmission of volatility between stock markets. Review of Financial Studies 3, 5-33.

Lee, S., Kim, K.J., 1993. Does the October 1987 crash strengthen the co-movements among national stock markets? Review of Financial Economics 3, 89-102. 
Levy, H., Lerman, Z., 1988. The benefits of international diversification in bonds. Financial Analysts Journal 44, 5664.

Longin, F., Solnik, B., 1995. Is the correlation in international equity returns constant: 1960-1990? Journal of International Money and Finance 14, 3-26.

Rigobon, R., 2003. Identification through heteroskedasticity. The Review of Economics and Statistics 85, 777-792. 